\title{
Work adjustment of cancer survivors: An organisational support framework
}

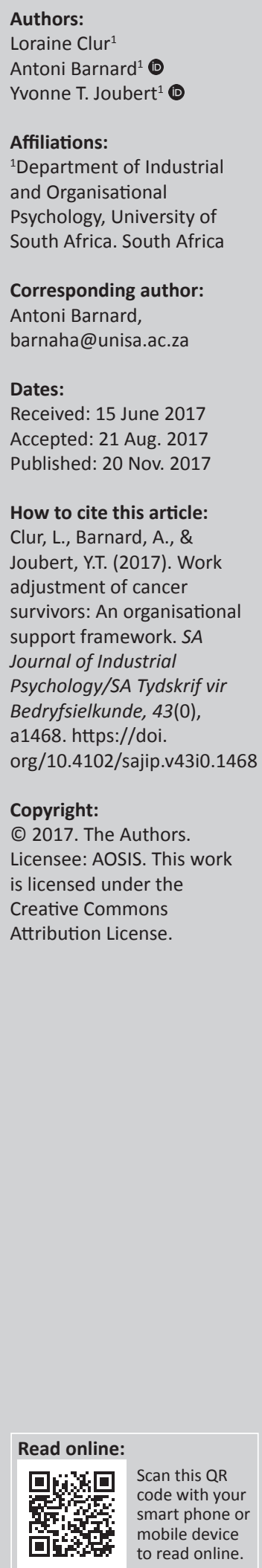

Orientation: Medical advancements increase incidents of cancer survivors returning to work. Work adjustment of cancer survivors is essential for job satisfaction and productivity and should be supported and facilitated by the organisation.

Research purpose: The purpose of the study was to explore cancer survivors' return to work experience in order to explicate organisational support needed to facilitate their successful work adjustment.

Motivation for the study: Despite the growing awareness of cancer survivorship, the challenges, expectations and management of the return to work process remain under researched.

Research approach, design and method: Heidegger's hermeneutic phenomenology formed the methodological foundation to the study. Purposive sampling was used to select eight participants from an oncology unit and cancer support organisation in the Southern Cape and Little Karoo regions. Participants, diagnosed with various types of cancer, were regarded as cancer survivors as they completed treatment and have returned to work. Data were collected using unstructured interviews and analysed through thematic analysis based on Ricoeur's hermeneutic phenomenological theory of interpretation.

Main findings: Results highlight four themes representing cancer survivors' needs for organisational support. The support needs are presented in the context of the theory of work adjustment in a hierarchical schema that evolves from a basic need for emotion-focussed support to the need for knowledge and for practical guidance. Support needs culminate in the need for self-actualisation through meaning-making. An organisational support framework is proposed consisting of four integrated functions aimed at addressing the needs that emerged from the data.

Practical and managerial implications: The organisational support framework provides guidance to develop an organisational policy and intervention strategy aimed at managing the successful work adjustment of the cancer survivor.

Contribution or value-add: The study presents original research, contributing to the body of knowledge regarding cancer survivors returning to work, and introduces a new area of research in the discipline of industrial and organisational psychology.

\section{Introduction}

Work adjustment is a constant challenge all employees contend with whilst striving to achieve job satisfaction and career success. Returning to work, after surviving a life-threatening cancer diagnosis and consequent invasive treatment, is moreover inevitably strenuous and distressing (Sarkar et al., 2015; Stanton, Rowland \& Ganz, 2015), and such cancer survivors require wideranging support to adjust successfully back into the workplace (Messner \& Vera, 2011).

Early diagnosis because of advanced medical screening and improved cancer treatments results in an increasing number of cancer survivors who return to work (RTW) (Grunfeld, Rixon, Eaton \& Cooper, 2008; Hoffman, 2005; Kennedy, Haslam, Munir \& Pryce, 2007; Mehnert \& Koch, 2013; Stergiou-Kita et al., 2016). Working is essential to personal meaning and psychological well-being (Blustein, 2008), and through work organisations help employees meet physical, social and psychological needs (Renfro-Michel, Burlew \& Robert, 2009). Cancer survivors RTW because of the financial and psycho-social benefits that working holds for them (Messner \& Vera, 2011; Steiner, Cavender, Main \& Bradley, 2004; Stergiou-Kita et al., 2016). For the cancer survivor, working provides independence and purpose (Messner \& Vera, 2011); it restores normality, 
routine, stability and social control (Clarke, 2015; Kennedy et al., 2007; Nowrouzi, Lightfoot, Cote \& Watson, 2009); it enhances their sense of self-worth, identity and social connectedness; and it boosts their emotional well-being and self-esteem (Knott et al., 2014).

Suffering or having suffered from cancer, however, invariably affects performance (Adler \& Page, 2008; Mitchell \& Bruen, 2008; Pullen, 2013) as cancer employees ${ }^{1}$ continue to be confronted by a range of physical, cognitive and emotional challenges (Barnard, Clur \& Joubert, 2016) potentially reducing their work ability (Munir, Kalawsky, Wallis \& Donaldson-Feilder, 2013) when they re-enter the workplace. Re-integration of the cancer survivor into the workplace has therefore become an important issue for both employers and employees (Nowrouzi et al., 2009) with inadequate research into the work-related needs of cancer survivors (Nitkin, Parkinson \& Schultz, 2011). Apart from medical and occupational health practitioners, line managers and colleagues constitute important role players involved in supporting the work adjustment of cancer survivors when they RTW (Yarker, Munir, Bains, Kalawsky \& Haslam, 2010). Employers, managers and colleagues, however, have a limited understanding of the physical and psycho-social challenges experienced by the cancer survivor (Messner \& Vera, 2011; Tamminga, De Boer, Verbeek \& Frings-Dresen, 2012) detracting from their role in and contribution to the successful RTW process. Such a lack of understanding leads to managerial incompetence, poor communication and inadequate RTW support in the work context (Kennedy et al., 2007; Yarker et al., 2010). Limited organisational understanding also emphasises the need for guidance on how to manage the cancer survivor in the workplace (Amir \& Brocky, 2009). Limited understanding of the cancer employee's RTW process may exaggerate the work adjustment challenges faced by cancer survivors. Studies exploring the RTW experiences of cancer survivors focussing on organisational support systems and interventions are therefore desperately needed to better facilitate work adjustment during the RTW process (Dewa et al., 2016; Fong, Murphy, Westbrook \& Markle, 2015; Tamminga et al., 2012).

The need for organisational support to facilitate the RTW process of cancer employees in the context of the rising number of cancer survivors motivated the researchers to embark on a study exploring cancer employees' RTW experience. The purpose of this study was to gain an understanding of the RTW experience in order to expound organisational support needed to facilitate successful work adjustment of the cancer employee throughout the RTW process.

\section{Conceptual framework}

Cancer survivors that RTW experience working limitations because of lingering physical, cognitive and emotional effects to employees who have returned to work after having been diagnosed with cance and having completed cancer treatment. of cancer and its treatment (Nitkin et al., 2011). Long after successful treatment, cancer survivors have to contend with physical impairments such as fatigue, general weakness, continued pain, bodily discomfort and hot flushes (Pullen, 2013). Cognitive difficulties in short-term memory, language expression and spatial abilities are frequently induced by cancer treatments (Adler \& Page, 2008), leaving the cancer employee to deal with uncertainty, sadness, shame (Messner \& Vera, 2011) and difficulties to re-establish working relationships with confidence (Main, Nowels, Cavender, Etschmaier \& Steiner, 2005). Fear of recurrence and related anxieties about performance and social image provide additional psychological challenges the cancer employee needs to contend with when trying to adjust to the workplace (Adler \& Page, 2008; Sarkar et al., 2015). Gudbergsson, Fossa, Borgeraas and Dahl (2006) found that cancer survivors reported more health problems and psychological challenges than other employees, raising concerns about the work adjustment of the cancer employee during the RTW process.

\section{Theory of work adjustment and successful return to work}

Successful RTW denotes successful work adjustment in the period consequent to cancer diagnosis and treatment (Barnard et al., 2016). The Theory of Work Adjustment (TWA) (Lofquist \& Dawis, 1969) aligns with principles underlying the theoretical frameworks of person-environment fit (Dawis \& Lofquist, 1984) or person-organisational fit (Bretz \& Judge, 1994; Greguras \& Diefendorff, 2009) and provides a relevant theoretical framework to understand the cancer employee's RTW process. TWA originated from vocational rehabilitation research (Lofquist \& Dawis, 1969) and evolved into a proactive theoretical framework used to anticipate and cope with adjustment (Leonard \& Schimmel, 2016). It has been singled out as one of the most robust and best validated theories in vocational psychology (Eggerth, 2008). Theories of person-environment (P-E) fit emphasise the need for correspondence between individual interests and abilities with the work environment, leading to appropriate career decisions and ultimately to job satisfaction and performance (Bretz \& Judge, 1994). Extending the P-E fit approach, the TWA equally values the contribution of both the individual and the work environment in affecting job satisfaction and performance (Wang \& Wanberg, 2017). The mutual fulfilment of the needs and expectations that the employee and the work context have of one another is expounded through the concepts of satisfaction and satisfactoriness (Eggerth, 2008). When the organisational system reinforces and fulfils the unique set of expectations and needs an individual brings to the work setting, satisfaction results. Satisfactoriness, on the contrary, results from the individual being capable to fulfil the requirements of the work (Leonard \& Schimmel, 2016). Successful work adjustment thus results when there is a match between individual values and needs and the reinforcers offered by the work environment, and when there is similarly a match between the skills and abilities of the individual and what the work environment requires (Leonard \& Schimmel, 2016). 
Work adjustment is conceptualised as a continuous and dynamic process that spans several sequential stages in employees' work life in an organisation, with each stage characterised by typical employee expectations of the work environment (Burlew, 2006). The process nature of RTW (Barnard et al., 2016) resonates with the concept of work adjustment as a process and begs an analysis of cancer survivors' typical needs and expectations throughout the RTW process in order to facilitate an understanding of what the organisation can do to support RTW.

\section{Coping strategies aimed at successful work adjustment}

Various motivation theories align with TWA principles as they point to the importance of maximising fit between individual needs and expectations with the work environment to enhance work motivation, morale and productivity (Bretz \& Judge, 1994; Eggerth \& Flynn, 2012). TWA furthermore conceptualises job stress as a result of the mismatch between work demands and resources with the employee needs and expectations (Eggerth, 2008). Individual coping behaviour, according to Krohne (2002), aims to manage stress-relevant P-E transactions by focussing either on changing internal states to fit the environmental demands (emotion-focussed coping) or on changing environmental realities causing stress (problemfocussed coping). This original distinction between emotionfocussed versus problem-focussed coping types by Folkman and Lazarus (1980) has evolved into variable perspectives to conceptualising coping (Krohne, 2002; Rothmann, Jorgensen \& Hill, 2011). What distinguishes emotion-focussed and problem-focussed coping from other strategies such as denial or avoidance is that the person addresses stress resulting from P-E mismatch whilst remaining in the situation physically, cognitively and emotionally. Similarly, through positive coping strategies such as meaning-making (Park, Edmonson, Fenster \& Blank, 2008), the employee manages the stressful circumstance, whilst remaining in it. Meaning-making coping strategies relate to Lent's (2004) model of restorative wellbeing which presents an integrative coping orientation to address resources internal to the person as well as external resources in the work environment, in order to attain adjustment. Coping strategies are usually regarded from the individual's perspective, yet form an important foundation in the TWA to understand what is required from an organisational support perspective to facilitate work adjustment.

Understanding cancer survivors' unique needs and expectations during the RTW process may therefore facilitate changes in the work environment to accommodate their needs and enhance their work motivation and morale. Application of TWA has moreover lead researchers to conclude that organisations should aid in the process of work adjustment by offering context-specific support (WilsonSmith \& Bates, 2014). Taking responsibility from an organisational perspective emphasises in this study the imperative role played by the organisation in guiding the successful RTW process. Beatty and Joffe (2006) emphasise employers' responsibility to the needs of employees who have to cope with a chronic disease. Varekamp et al. (2009) suggested that the clarification of challenges, communication and problem-solving could help in managing successful work adjustment of the cancer employee. Organisational support improves the RTW experience and can reduce the possibility and extent of cancer-related work impairments during RTW (Van Muijen et al., 2013).

\section{Contribution of the study}

From the literature reviewed whilst executing and reporting on this study, it seems that cancer survivorship is predominantly studied in the health sciences and in the field of social work. Yet, understanding the RTW process of cancer employees is imperative in the context of industrial and organisational psychology (IOP). As a discipline, IOP concerns itself with facilitating employees' work adjustment and optimal functioning in the work context. This article highlights a unique field of study in the discipline of IOP. In light of various researchers pointing out the continued need for research on the RTW process (Knott et al., 2014), this study contributes to the body of knowledge supporting cancer survivors' successful work adjustment during RTW. Pragmatically, the study provides valuable guidance to employers in managing the cancer employees' RTW process with the aim of optimising successful work adjustment during this time.

\section{Research design}

The methodological orientation in this study was based on the philosophical notions underlying Heidegger's hermeneutic phenomenology, and congruently, Ricoeur's process of interpreting and ascribing meaning to narrated lived experience in order to understand the central nature of that experience (Tan, Wilson \& Olver, 2009) was applied. Aligning with Heidegger's existential ontology of 'Dasein' enables us (the researchers) to see people in the way they understand themselves (Davidsen, 2013). Epistemologically, Heidegger's hermeneutic phenomenological approach emphasises interpretation as a co-construction or 'a fusion' of meaning derived from the lifeworlds of both researcher and researched (Crowther, Ironside, Spence \& Smythe, 2017, p. 831). A hermeneutic phenomenological stance therefore assumes that in all description of lived experience already lies interpretation and meaning-making (Davidsen, 2013) inevitably influenced by researcher preconceptions (Laverty, 2003). As such, the findings in this study reflect meaning derived in the current research context and form the conceptual framework presented here. This study used qualitative research methods to illicit narrative experiences reflecting the lived RTW experiences of cancer employees in the conceptual context of successful work adjustment.

\section{Research setting}

This study was performed at a private oncology unit and at a cancer support organisation set in the Southern Cape and Little Karoo regions of South Africa. 


\section{Entrée and establishing researcher roles}

The clinical practice manager at the oncology unit and the medical sister at the cancer support institution acted as the gatekeepers to the study. Permission was obtained from management in both organisations to put up posters of the study in their reception areas, and permission was given to the gatekeepers to contact and inform cancer survivors of the study. Upon consent, the contact detail of interested participants was made available to the researchers of the study. At initial contact prior to interviews, the aim and nature of the study and relevant ethical issues such as protection of anonymity, confidentiality and the freedom to withdraw were explained to participants. These aspects were confirmed again during interviews at which time consent to digitally record interviews was also obtained. As confirmation of their understanding and consent to the study, all participants signed an informed participant consent form. Arrangements were also made with the gatekeepers for counselling referral should the need arise consequent to the interviews and participants were made aware of this opportunity.

\section{Sampling and participants}

Purposive sampling (Laher \& Botha, 2012) was applied to incorporate participants with rich lived experience in the phenomenon under study (Laverty, 2003), namely RTW after cancer diagnosis and treatment. As such, sampling criteria required participants to have been diagnosed with cancer, having completed surgery and/or cancer treatment and having returned to the workplace. Eight cancer survivors participated in unstructured interviews (lasting between 45 and 60 min each). Participant demographics, occupational type, type of cancer and time period since diagnosis are summarised in Table 1. Code numbers (P1-P8) were assigned to protect participant confidentiality and preserve anonymity.

\section{Data collection}

Congruent to hermeneutic phenomenological research, data were collected through unstructured interviews in order to elicit personal stories of lived experience pertaining to the research phenomenon (Crowther et al., 2017). The unstructured interview aided the researchers to focus interview discussions on the RTW process whilst remaining open to any specific participant insights regarding their work-life experiences as a cancer survivor. One open-ended question, 'Please tell me about your experience when you returned to work after treatment' was asked. To obtain a rich description of the participants' experiences, follow-up probes were focussed on requesting participants to elaborate on thoughts and feelings regarding their RTW journey, the challenges they experienced during this time and the support they needed and received in and around the workplace.

\section{Data analysis}

Following the principles in Ricoeur's framework of interpretation (see Svenningsen, Egerod \& Dreyer, 2016; Tan et al., 2009), data were thematically analysed based on a fusion of meaning from the data with the researchers' preconceived conceptual frameworks. Firstly, distanciation (see Dreyer \& Pedersen, 2009) was obtained by separating the spoken discourse from the participants' context and intention, through transcription of digitally recorded interviews. Appropriation (see Tan et al., 2009) was obtained through constant reflexive consultations within the research team on understanding their orientations and what they bring to the data when they attempt to interpret it. In moving iteratively between the content of the text and the researchers' preconceived conceptual frameworks, data analysis operationalised what Heidegger (1967) referred to as the hermeneutic circle or Ricoeur's concept of the hermeneutic arc (Tan et al., 2009). Stages of data analysis included (see Tan et al., 2009) an initial naive reading and descriptive explanation of what the text was saying about the RTW process; a thematic interpretation by integrating researchers' theoretical preconceptions to add meaning to what the text was saying about the RTW process and by grouping related units of meaning; and developing in-depth understanding by moving back and forth between the initial explanation, the thematic interpretation and the researchers' preconceived conceptual framework. Results from the thematic interpretation and the researchers' in-depth understanding of how organisations can support the adjustment of cancer employees during RTW are reported here.

\section{Reporting}

Findings are reported using a qualitative writing style depicting meaning by weaving researcher interpretations with rich, verbatim text from participants' narratives.

TABLE 1: Descriptive profile of the research participants.

\begin{tabular}{|c|c|c|c|c|c|c|c|}
\hline Participant number & Gender & Age & Race & Occupation & Type of cancer & $\begin{array}{c}\text { Time since cancer } \\
\text { diagnosis }\end{array}$ & Marital status \\
\hline P1 & Male & 28 & $\mathrm{MR}$ & Forensic Pathology Officer & Lymph node cancer & 4 years & $\mathrm{s}$ \\
\hline P2 & Female & 59 & $\mathrm{MR}$ & Teacher & Breast & 5 years & M \\
\hline P3 & Female & 57 & w & Cashier & Breast & 7 years & M \\
\hline P4 & Female & 39 & W & Sales assistant & Breast & 2 years & D \\
\hline P5 & Female & 45 & w & Community mobiliser & Breast & 8 years & M \\
\hline P6 & Female & 40 & W & Personal assistant & Cervical & 6 years & M \\
\hline P7 & Male & 44 & w & Deputy Director Administration Support & Hodgkin's lymphoma & 2.5 years & M \\
\hline P8 & Female & 47 & B & Operational Manager (Hospital) & Stomach (metastatic cancer) & 3 years & S \\
\hline
\end{tabular}

MR, Mixed race; $W$, white; $B$, black; $S$, single; $D$, divorced; $M$, married. 


\section{Findings}

Immersion into the data, conscious of the dynamics of satisfaction as a core conceptual element and dynamic in the TWA (Eggerth, 2008), revealed a variety of needs unique to the cancer survivor and how they cope with their RTW process. Influenced thus by the conceptual framework of the TWA and its conception of satisfaction and of successful adjustment led to identifying four core themes that demonstrate the unique organisational support needs of the cancer employee during RTW, namely: (1) a need for emotion-focussed support, (2) a need for support to enhance knowledge and understanding, (3) a need for practical guidance and support and (4) a need for self-actualisation through meaning-making. The discussion below is built on the thematic structure and illuminates the meaning derived from the data.

\section{A need for emotion-focussed support}

Early in the RTW process, cancer employees project a strong need for emotion-focussed support resulting from them feeling misunderstood, overwhelmed and unsure when re-entering the work context. The unexpected physical and emotional challenges they now have to confront change what was normally a very familiar setting to them. Adjusting to the uncertainty and themselves being different in the same work setting challenges their sense of self and worth in the work context. Heightened emotions are evident, dominated by the fear that they will not be able to cope and do what is expected of them as before. In coping with their anxiety, participants speak of not being understood and supported, of feeling alone and afraid - evidenced in the translated verse of Participant six:

While the black truth mocks me

Its cold fingers running over me

I cringe in solitude

with ever-rising doubt

Is this lonely abandonment

keeping me prison

Another participant spoke freely of her struggles, but then suddenly denied any difficulties at work, immediately reverting back to her disappointment with not being supported at home. The emotional reaction seemed to portray both denial and projection of her needs to the work environment; she said:

'You know what, I'd rather not talk about my employer. But my husband! I do not know whether he is in denial but for him it was always so I can still make that stuff - he wants me to still continue as before. My children they want something and then I make it. They make if there is nothing wrong.' [P2]

Later Participant two however talks about feeling misunderstood in the work environment:

'Some employers do not understand. It puts people down and they feel pushed aside. You cannot do what you did previously and now you are forced to do otherwise.' [P2]
Similar to Participant two in the previous paragraph, Participant three feels that others do not understand her situation and she is not sure whether she will cope, feeling quite emotional:

'I'm more emotional than before. Also struggling to remember at times, but a person has to adapt to it. It's sometimes difficult (tears). It's a big adjustment and I don't think you ever come over it. It's difficult for others, you look healthy, but they don't know what is going on here inside. Think you must just carry on as before.' [P3]

The need for support is therefore further evidenced in how participants question themselves and their value. In reflecting such self-doubt, they present with feelings of uncertainty, isolation (misunderstood) and dejection. Lowered mood is reflected in the words of Participant four:

'I'm very emotional I have had a mild pill because I feel so down, in a deep pit.' [P4]

In expressing a need for their employers to provide them with more emotion-focussed support, participants thus wanted more sympathy and understanding and suggested that there should be more encouragement, opportunities for counselling and that the employer should provide more tangible support. Participant one suggested, for example, that employers should provide more encouragement:

'They must motivate a person more. If there is no motivation you feel they are not interested or do not have knowledge about the illness.' [P1]

Participant six also felt that employers should provide opportunities for counselling:

'It's actually something that needs to be considered [counselling]. It is a deep hole into which you suddenly are thrown. And if you do not get out, then what.' [P6]

and continues to express a need for sympathy and understanding from her employer:

'If a person needs more time, to have sympathy with that person, whether it is unpaid leave or whatever, it will help.' [P6]

Cancer employees seem to be dependent on others in the work environment for affirmation that everything will be fine and that they are still of value to the employer and to coworkers.

\section{A need for support through enhancing knowledge and understanding}

When becoming more familiar with the new experience of the previously familiar work environment, cancer employees move towards acceptance of their new work-life situation. During this time, they seem to demonstrate a more rational approach to dealing with RTW and express a need for more information to understand what is happening to them and how they can more positively deal with the situation. Some participants specifically noted a need for the provision of relevant information at the workplace to assist both the employer and themselves in the RTW process as noted by Participant one: 
'They need to do more research on the disease and ask questions. As I always tell people, cancer is not like other chronic diseases.' [P1]

Participant six, for example, ascribed her employer's unrealistic expectations to a lack of knowledge:

'We that sit in reception and customer service position, feel after six weeks still not right. You're still bone tired, and you must render a service and it must look as if nothing is wrong. The image you at all time must keep up...it takes more mental energy and strength to keep the image up.' [P6]

Similarly, Participant two mentioned information as beneficial:

'Information would be good thing to do, will help people at workplaces.' [P2]

Focussing on how he utilised dietary information to help him manage his physical deterioration and consequently gain a more positive outlook on managing his health, Participant seven demonstrates the importance of knowledge:

'The oncologist, he said you should eat what you can get in. And it is really so... then I deviated quite a bit, but I've been going on with my carrot juice and stuff like that. So that's the pre and the post is definitely another thing I struggled with. I have the thing you've had gotten a second chance. I know if I am going to boost my body with the right food I can definitely recover the damage that is done within me. I can recover because that's how our bodies work I have to give it enough fuel.' [P7]

During this stage, there is a conscious expression of needing knowledge and understanding to cognitively cope with previous uncertainties, lessening the anxiety that it created. As such Participant five attended a workshop enhancing her cancer-related health knowledge and she acknowledges:

I saw how bad this unhealthy belief was and they give you the tools to change it.' [P5]

Through knowledge participants want to confront their fears, feel more in control and experience more positive affectivity.

\section{A need for guidance and directive support}

As a result of becoming more accepting of and positive towards their situation cancer employees re-appraise and rephrase their situation in more positive ways and consciously start to seek strategies and activities to help them address the work-related challenges they experience physically and socially. Their need in this stage relates to requiring problemfocussed support where participants were motivated to take action to address work environment realities to facilitate their adjustment. This need for practical guidance and directive support was evident in participants mentioning work-related strategies such as open communication, the setting of clear goals and feedback on their work performance. Participant two worked in an organisation where she felt free to express her needs and openly communicate mutual expectations:

'If something like this happens [cancer], you should be open. I told my supervisor how I felt and thought and he understood.' [P2] and Participant six said:

'Keep open door as needed for that person if he cannot return after those six weeks - that it will be discussed beforehand.' [P6]

Participants realistically acknowledge significant changes in their work performance such as relaxed attitude on task completion and deadlines (P4), limited physical capability because of fatigue, pain and physical discomfort (P1, P5 and P6) and reduced memory and concentration (P2, P3 and P7). Yet, they still want to pursue a career and find value in working:

'So for me going back to work and getting busy, it was nice. It was very nice... I want to do everything as before I was diagnosed with cancer.' [P8]

Similarly Participant five had the expectation of a promotion in the following year. The furthering of her career met her expectation to be regarded as valuable, yet she needed guidance on expectations regarding her work performance and career prospects in the context of her dealing with cancer-related challenges at work. The issue of reverting to organisational policies and procedures to support coping is included here and reflected on in the story of Participant eight, demonstrating how her employer supported her through procedural activities and the availability of a special leave policy:

'My employer all of them starting from the general worker, my colleagues, everybody is so supporting... it's more than I was expecting. They gave me all the time off, even the sick leave forms they brought to hospital and when I had to extend my sick leave they brought it. They advise me to use Pillar it's some kind of incapacity leave. You take your leave your sick leave, when it's finished, you apply for Pillar. They brought that forms themselves for me at home.' [P8]

\section{A need for self-actualisation through meaning- making}

Active and conscious coping with the RTW process seem to grow self-confidence and participants express a need for purpose and meaning through work. They reflect on their personal growth and value as the pinnacle of their work adjustment during RTW, as reflected in the words of Participant five:

'Emotional or personality-wise, I'm less self-centred than before. I've more compassion with other people. I have more patience than before. I experience pretty things, nice things more intensely than I perhaps would have done previously. I'm more grateful, uhm and I'm stronger emotionally.' [P5]

Such personal growth enables the cancer employee to have a meaningful impact on the lives of others in the work context. Here P1 (himself working with cancer patients) muses:

'Now it's easier to work with cancer patients. I can motivate them because I was in the situation myself and tell them how it's been for me. I have more understanding since I was in the same situation.' [P1]

Similarly Participant two values her contribution to others as a result of her cancer experience: 
'I came almost as one that give witness to all my staff and again afterwards I spoke to women.' [P2]

It seems that participants move from questioning own value and purpose in initial RTW stages to appreciating life's meaning and their purposeful self-worth in last phase. The critical illness makes them aware of their mortality and causes the cancer survivor to value time differently, wanting to spend it meaningfully. Some of the participants indicated that they feel they would like to spend more time with their family ('...you know it is borrowed time we spent with each other' [P7]), and others wanted to focus more on engaging in meaningful work, such as Participant two expressing the need to help others through their experience and volunteer work:

'one that give witness to all my staff and again afterwards I spoke to women' [P2]

and:

'I had a talk at relay for life....' [P6]

At this stage, participants express needs that are more intrinsic in nature, calling for a work environment that empowers them to contribute purposefully to the work environment, colleagues and others in general. For the cancer employee, the need for self-actualisation derives from finding meaning, purpose and self-worth through the cancer and RTW experience. The organisation should provide the cancer employee with opportunities to fulfil such self-actualisation needs by involving them in meaningful work where they have an impact on others' coping with work-life experiences. Examples of coping with RTW by finding meaning through spiritual or religious expression relate here. Participant seven expresses his acceptance of reality and how he copes with it through believing:

'He writes in the bible he protects you under his wings, and these types of things, because the things go through your head. And because I am a believer, the other believers come and tell you all sorts of things like not seeing the bigger picture and [ask] do you understand? A guy who hasn't got it, deals with the illness (laughs) but you know we don't deal with the illness we deal with the disease and also have this faith crisis that we have to run through. And I will tell you honestly it's not my faith that healed me. My faith in the grace of Jesus is the thing that made the difference. It gave me calm.' [P7]

\section{Discussion}

The cancer employee returning to work presents a unique work adjustment state in that changes within the individual and not in the work environment have compromised P-E fit. Despite an unchanged work-environment, the employees' resources, abilities and life orientation have fundamentally changed. To cope with resulting work adjustment challenges, the needs of cancer employees evolve during the RTW process, from emotion-focussed needs in the early RTW stages to problem-focussed and ultimately selfactualisation needs as the RTW process unfolds. Evolving needs do not replace previous needs, but rather seem to build on initially expressed needs. The evolving need dynamic forms a mental image almost similar to the needs hierarchy of Maslow, demonstrating the support that the cancer employee requires to adjust successfully - from a basic level towards more advanced levels. The four main themes are therefore depicted in Figure 1 as a hierarchy of needs fundamental to successful work adjustment during the RTW process.

Reflecting critically on the evolving coping needs of the cancer employee during RTW in light of the stated research purpose to expound organisational support needed to facilitate successful work adjustment during RTW revealed four related organisational support functions, namely motivation, information, navigation and stabilisation. The functions of organisational support are shown in Figure 2, and each is aimed at addressing the work adjustment of the

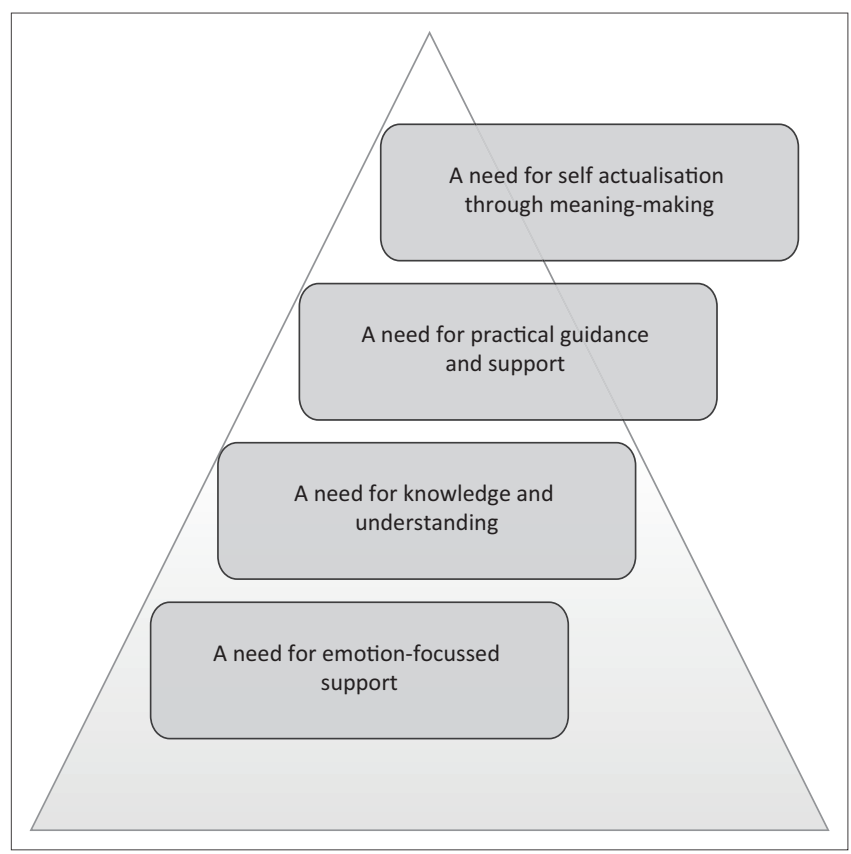

FIGURE 1: Hierarchy of needs for successful adjustment during return to work.

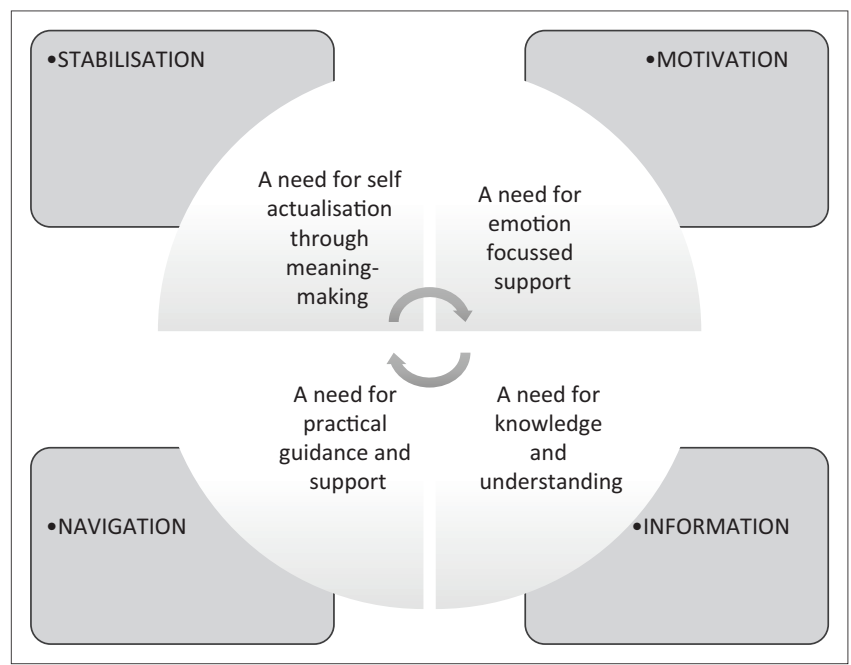

FIGURE 2: Organisational support functions during return to work. 
cancer employee in line with their evolving RTW coping needs.

\section{Motivation as a management tool to facilitate adjustment}

Initially, cancer employees that RTW present with negative emotions and lowered mood, requiring motivation to adjust and function optimally in the work environment. In this stage, the expectations regarding organisational support focus on the emotional needs of the cancer survivor to feel understood, supported and valued. Motivation is defined by Latham and Pinder (2005, p.486) as 'a psychological process resulting from the interaction between the individual and the environment $t^{\prime}$ and fundamentally includes addressing affective-cognitive drivers of behaviour. To address the need for understanding, organisations should provide emotional support through counselling but also tangible support in the form of more time off, to demonstrate understanding of the cancer employee's challenges. Motivation can be attained through flexible management practices and work arrangements, allowing the cancer employee to dictate what they are capable of and when, keeping them occupied, considering flexitime or working from home, revising leave benefits, creating transitional work, looking at work site accommodation and providing counselling services through an employee assistance programme (EAP). Tangible support demonstrates understanding and establishes the organisation's investment to facilitate the adjustment process for the cancer employee to regain direction and self-confidence at work.

\section{Using information in facilitating cancer survivors' work adjustment}

The participants already had reasonable knowledge about their illness and the prognosis, yet they voiced the need for continued information. According to Varekamp et al. (2009), the organisation can empower cancer survivors by increasing their knowledge and skills, thus enabling them to take responsibility for finding solutions to challenges in the workplace. Participants also emphasised the importance of information for their employers and co-workers to facilitate understanding and decision-making relevant to the cancer employee's work adjustment. Previous studies also indicate that line managers and colleagues should be equipped with information regarding the cancer survivor's work ability to be able to give the necessary support (Popa, 2015; Yarker et al., 2010). The participants experience knowledge about the disease as an important requirement for both employers and co-workers in the RTW process. Similarly, Popa (2015) notes that proper information will lead to awareness and will generate pro-active behaviour and supportive attitudes in the work environment.

\section{Navigation as management approach to return to work}

Navigation is aimed at providing cancer employees with practical guidance in the work environment through open communication of mutual performance expectations, revised career goals, performance feedback, skills training and availability of relevant organisational policies and procedures. Navigation as a management approach directs a joint employer-employee responsibility where cancer employees feel safe to communicate their limitations and needs and the employer communicates performance expectations and reasonable work accommodations. By setting clear goals and giving regular feedback, the cancer employee can make suggestions and adjustments to improve work outcomes.

In response, the organisation should allow alternative work accommodation and provide practical benefit strategies by revising leave benefits and work hours and creating transitional work (Mitchell \& Bruen, 2008). In this regard, Ross (2007) introduced vocational rehabilitation as an important approach to assist the cancer employees' adjustment during RTW. Vocational rehabilitation includes a wide range of interventions such as an assessment of cancer employees' needs, re-training, RTW management by employers and reasonable adjustments in work structure and design (Ross, 2007). Clark and Stovall (1996) add hereto interventions that focus on building skills and coping strategies. An organisational policy framework and a RTW programme assisting cancer employees with tangible guidance regarding resources and procedures available to ease their adjustment seem essential. Apart from clarifying available resources and support and how to access these, a policy guides management to ensure that cancer employees are managed in a consistently fair manner (Nowrouzi et al., 2009). The RTW policy should delineate relevant RTW adjustment information (Popa, 2015), emotional support and resources available, a tailored performance management procedure and allowance of alternative work accommodation or job restructuring.

\section{Stabilisation: Facilitating adjustment holistically}

In reaching the final stages of adjustment, cancer employees rely on meaning-making through spiritual understanding, spending time meaningfully and giving to others, to cope with their situation. During this stage, the cancer survivor begins to balance himself or herself somewhere between the old and new self, integrating a stable and adjusted self. The opportunity to express beliefs, religion, spirituality and volunteering should be provided, and adjustment interventions should focus on psychological and spiritual well-being. For cancer survivors, meaningfulness goes beyond the workplace and is more about finding a connection to humanity through their jobs (Bailey \& Madden, 2016). Organisations can encourage this by creating a culture of ethics, morals and corporate social responsibility that brings an employee's personal values and work life together (Bailey \& Madden, 2016). Workplace stability can be achieved by facilitating positive change processes and also by providing a meaningful or purposeful career as a whole.

Ultimately, as the cancer survivor moves through the hierarchical needs stages in the RTW process, it is necessary 
to provide an integrative RTW management approach to stabilise their experience of having their hierarchy of needs addressed. Addressing their needs from an integrative perspective will enable them to self-actualise as a cancer survivor with a meaningful or purposeful career. Hryniuk and Waechter (2011) suggest that a comprehensive cancer assistance programme will enable employers to navigate cancer employees through the RTW process to ensure successful work adjustment.

\section{Conclusion and recommendations}

This study has drawn on the lived RTW experience of cancer survivors to illuminate organisational support required to facilitate successful work adjustment. Cancer employees presented with various needs that present in a hierarchical schema during the RTW process. The process nature of RTW (Barnard et al., 2016) and of work adjustment (Burlew, 2006) sets the foundation for understanding cancer employees' RTW needs as building on one another. During RTW, the cancer employee progresses in terms of successful work adjustment when the basic need of emotional support is met towards addressing more rational problem-focussed needs such as information and practical guidance and support resources. Ultimately, successful adjustment seems to be facilitated by fulfilling the self-actualisation needs of the cancer employee. Similar to the assumptions underlying the motivational theory of Maslow (1943), cancer employees' needs in the proposed hierarchical schema are interrelated and should be approached holistically. ${ }^{2}$ All RTW needs are present at any particular point in time and may have been met to certain degrees of satisfaction. As such, cancer employees oscillate between the different need levels, yet higher levels of satisfaction of emotional support precede the importance of the needs that follow. Cancer employees thus move progressively towards self-actualisation through meaning-making as the ultimate reflection of successful work adjustment.

From a TWA perspective, successful work adjustment is dependent of accommodations made by the organisation to address cancer employees' needs. Theorising about the needs of cancer employees in the proposed hierarchical schema requires a holistic organisational support approach that integrates the functions of motivation, information, navigation and stabilisation (as depicted in the organisational support framework in Figure 2). We therefore conclude that organisations should develop a culture that is supportive of the work adjustment of cancer employees. A culture of clear communication and early, holistic intervention will reflect an organisation's commitment to continued employment of the cancer survivor. In demonstrating such a supportive culture, an integrated health promotion programme similar to the conventional EAPs (see Attridge

\footnotetext{
2.According to Maslow (1943), a need does not emerge only after a lower order need has been satisfied. Rather, all needs are present at any point in time in differing degrees of satisfaction proportionately distributed across the needs hierarchy. degrees of satisfaction proportionately distributed across the needs hierarchy.
Behaviour is driven by gradually increasing satisfaction of lower order needs, Behaviour is driven by gradually increasing satisfaction of lowe
whereas higher order needs become progressively more important.
}

2012) should be tailored to facilitate successful work adjustment of the cancer employee.

\section{Ethical consideration}

The study received ethical clearance from the Institutional Ethics Committee of the University of South Africa (reference number 2014/CEMS/IOP/011) and was conducted under the ambit of the ethics policy of UNISA (2013).

\section{Acknowledgements}

The authors would like to acknowledge the participants who shared their stories with them in this study as well as the private oncology unit and cancer support organisation for assisting in gaining access to the participants and availing their offices for interviews.

\section{Competing interests}

The authors declare they have no competing financial or personal relationships that may have influenced them inappropriately in writing this article.

\section{Authors' contributions}

The authors collaboratively designed the research project, with A.B. being the project leader. L.C. was responsible for data gathering, literature review and results. A.B. constructed the conceptual framework and contributed to the methodology and data analysis. L.C. and A.B. wrote the final manuscript, and Y.T.J. was responsible as critical reader throughout the research process and writing up of the results.

\section{References}

Adler, N.E., \& Page, A.E.K. (Eds.). (2008). Cancer care for the whole patient: Meeting psychosocial health needs. Washington, DC: National Academies Press (US).

Amir, Z., \& Brocky, J. (2009). Cancer survivorship and employment: Epidemiology. Occupational Medicine, 59, 373-377. https://doi.org/10.1093/occmed/ kqp086

Attridge, M. (2012). Employee assistance programs: Evidence and current trends. In R.J. Gatchel \& I.Z. Schultz (Eds.), Handbook of occupational health and well-ness (pp. 441-467). New York: Springer.

Bailey, C. \& Madden, A. (2016). What makes work meaningful or meaningless. MIT Sloan Management. Retrieved May 10, 2017, from http://sloanreview.mit.edu/ article/what-makes-work-meaningful-or-meaningless/

Barnard, A., Clur, L., \& Joubert, Y.L. (2016). Returning to work: The cancer survivor's transformational journey of adjustment and coping. International Journal of Qualitative Studies on Health and Well-being, 11, 32488. https://doi.org/10.3402/ qhw.v11.32488

Beatty, J.E., \& Joffe, R. (2006). An overlooked dimension of diversity: The career effects of chronic illness. Organizational Dynamics, 35(2), 182-195. https://doi.org/ 10.1016/j.orgdyn.2006.03.006

Blustein, D.L. (2008). The role of work in psychological health and well-being: A conceptual, historical, and public policy perspective. American Psychologist, 63(4), 228. https://doi.org/10.1037/0003-066X.63.4.228

Bretz, R.D., \& Judge, T.A. (1994). Person-organization fit and the theory of work adjustment: Implications for satisfaction, tenure, and career success. Journal of Vocational Behavior, 44(1), 32-54. https://doi.org/10.1006/jvbe.1994.1003

Burlew, L.D. (2006). Successful work adjustment: A life span approach. New York: Nova Publishers.

Clark, E.J., \& Stovall, E.L. (1996). Advocacy: The cornerstone of cancer survivorship. Cancer Practice, 4(5), 239-244.

Clarke, D.M. (2015). Stress and the total disease: Supporting employees after cancer. British Safety Council: Safety Management. Retrieved May 7, 2017, from https:// $\mathrm{sm}$.britsafe.org/stress-and-total-disease-supporting-employees-after-cancer 
Crowther, S., Ironside, P., Spence, D., \& Smythe, L. (2017). Crafting stories in hermeneutic phenomenology research: A methodological device. Qualitative hermeneutic phenomenology research: A methodological device. Qualitative
Health Research, 27(6), 826-835. https://doi.org/10.1177/1049732316656161

Davidsen, A.S. (2013). Phenomenological approaches in psychology and health sciences. Qualitative Research in Psychology, 10(3), 318-339. https://doi.org/10. 1080/14780887.2011.608466

Dawis, R.V., \& Lofquist, L.H. (1984). A psychological theory of work adjustment. Minneapolis, MN: University of Minnesota Press.

Dewa, C.S., Trojanowski, L., Tamminga, S.J., Ringash, J., McQuestion, M., \& Hoch, J.S (2016). Advice about work-related experiences of head and neck cancer survivors: An exploratory and descriptive qualitative study. PLoS One, 11(4), 1-13. Retrieved May 5, 2017, from http://journals.plos.org/plosone/article?id=10.1371/journal. pone.0152944

Dreyer, P.S., \& Pedersen, B.D. (2009). Distanciation in Ricoeur's theory of interpretation Narrations in a study of life experiences of living with chronic illness and home mechanical ventilation. Nursing Inquiry, 16(1), 64-73. https://doi.org/10.1111/ j.1440-1800.2009.00433.x

Eggerth, D.E. (2008). From theory of work adjustment to person-environment correspondence counselling: Vocational psychology as positive psychology. Journal of career assessment, 16(1), 60-74. https://doi.org/10.1177/106907270 7305771

Eggerth, D.E., \& Flynn, M.A. (2012). Applying the theory of work adjustment to Latino immigrant workers: An exploratory study. Journal of career development, 39(1), 76-98. https://doi.org/10.1177/0894845311417129

Folkman, S., \& Lazarus, R.S. (1980). An analysis of coping in a middle-aged community sample. Journal of Health and Social Behaviour, 21(3), 219-239. https://doi. org/10.2307/2136617

Fong, C.J., Murphy, K.M., Westbrook, J.D., \& Markle, M.M. (2015). Psychological interventions to facilitate employment outcomes for cancer survivors: A systematic review and meta-analysis. Research on Social Work Practice, OnlineFirst, 1-15. Retrieved May 10, 2017, from http://journals.sagepub.com/ OnlineFirst, 1-15. Retrieved May 10,
doi/abs/10.1177/1049731515604741

Greguras, G.J., \& Diefendorff, J.M. (2009). Different fits satisfy different needs: Linking person-environment fit to employee commitment and performance using selfdetermination theory. Journal of Applied Psychology, 94(2), 465-518. https://doi. org/10.1037/a0014068

Grunfeld, E.A., Rixon, L., Eaton, E., \& Cooper, A.F. (2008). The organisational perspective on the return to work of employees following treatment for cancer. Journal of Occupational Rehabilitation, 18(4), 381-388. https://doi.org/10.1007/ s10926-008-9152-1

Gudbergsson, S.B., Fossa, S.D., Borgeraas, E., \& Dahl, A.A. (2006). A comparative study of living conditions in cancer patients who have returned to work after curative treatment. Support Care Cancer, 14(10), 1020-1029. https://doi.org/10.1007/ s00520-006-0042-9

Heidegger, M. (1967). Being and time. Oxford, UK: Basil Blackwell.

Hoffman, B. (2005). Cancer survivors at work: A generation of progress. CA: A Cancer Journal for Clinicians, 55(5), 271-280. https://doi.org/10.3322/canjclin.55.5.271

Hryniuk, W., \& Waechter, M. (2011). Moving forward: Helping employees find their way through the challenges of cancer diagnosis, treatment and recovery. Benefits Canada, 35(9), 39-41.

Kennedy, F, Haslam, C., Munir, F., \& Pryce, J. (2007). Returning to work following cancer: A qualitative exploratory study into the experience of returning to work following cancer. European Journal of Cancer Care, 16(1), 17-25. https://doi. org/10.1111/j.1365-2354.2007.00729.x

Knott, V., Zrim, S., Shanahan, E.M., Anastassiadis, P., Lawn, S., Kichenadasse, G., et al. (2014). Returning to work following curative chemotherapy: A qualitative study of return to work barriers and preferences for intervention. Supportive Care in Cancer, 22(12), 3263-3273. https://doi.org/10.1007/s00520-014-2324-y

Krohne, H.W. (2002). Stress and coping theories. International Encyclopedia of the Social Behavioral Sciences, 22, 15163-15170.

Laher, S., \& Botha, A. (2012). Methods of sampling. In C. Wagner, B. Kawulich, \& M Garner (Eds.), Doing social research: A global context (pp. 86-100). London McGraw-Hill Higher Education.

Latham, G.P., \& Pinder, C.C. (2005). Work motivation theory and research at the dawn of the twenty-first century. Annual Review of Psychology, 56, 485-516. https:// doi.org/10.1146/annurev.psych.55.090902.142105

Laverty, S.M. (2003). Hermeneutic phenomenology and phenomenology: A comparison of historical and methodological considerations. International Journa of Qualitative Methods, 2(3), Article 3, 1-29. Retrieved February 20, 2016, from http://www.ualberta.ca/ iiqm/backissues/2_3final/pdf/laverty.pdf

Lent, R.W. (2004). Toward a unifying theoretical and practical perspective on wellbeing and psychosocial adjustment. Journal of Counseling Psychology, 51(4), 482. being and psychosocial adjustment. Journal of
https://doi.org/10.1037/0022-0167.51.4.482

Leonard, J.M., \& Schimmel, C.J. (2016). Theory of work adjustment and studentathletes' transition out of sport. Journal of Issues in Intercollegiate Athletics, 9, 62-85.

Lofquist, L., \& Dawis, R.V. (1969). Adjustment to work. New York: Appleton Century Crofts.

Main, D.S., Nowels, C.T., Cavender T.A., Etschmaier, M., \& Steiner, F. (2005). A qualitative study of work and work return in cancer survivors. Psycho Oncology, 14, 992-1004. https://doi.org/10.1002/pon.913

Maslow, A.H. (1943). A theory of human motivation. Psychological Review, 50(4), 370-396. https://doi.org/10.1037/h0054346
Mehnert, A., \& Koch, U. (2013). Predictors of employment among cancer survivors after medical rehabilitation - A prospective study. Scandinavian Journal of Work after medical rehabilitation - A prospective study. Scandinavian Journal of
Environmental \& Health, 39(1), 76-87. https://doi.org/10.5271/sjweh.3291

Messner, C., \& Vera, T. (2011). Cancer and the workplace. Continuing Education, 4(6), $24-26$.

Mitchell, K., \& Bruen, P.J. (2008). Beyond the disease: Seeking a quality of work life for cancer survivors - An invitation to employers. Unum. Retrieved May 7, 2017, from http://unum.newshq.businesswire.com/sites/unum.newshq.businesswire.com/ files/white_paper/file/Beyond the_Disease.pd

Munir, F., Kalawsky, K., Wallis, D.J., \& Donaldson-Feilder, E. (2013). Using intervention mapping to develop a work-related guidance tool for those affected by cancer. BMC Public Health, 13(6), 1-13. Retrieved May 10, 2017, from https:// bmcpublichealth.biomedcentral.com/articles/10.1186/1471-2458-13-6

Nitkin, P., Parkinson, M., \& Schultz, I.Z. (2011). Cancer and work: A Canadian perspective. Canadian Association of Psychosocial Oncology. Retrieved May 20, 2017, from http://www.capo.ca/pdf/CancerandWork-ACanadianPerspective.pdf

Nowrouzi, B., Lightfoot, N., Cote, K., \& Watson, R. (2009). Workplace support for employees with cancer. Current Oncology, 16(5), 15-22. https://doi.org/10.3747/ co.v16i5.381

Park, C.L., Edmondson, D., Fenster, J.R., \& Blank, T.O. (2008). Meaning making and psychological adjustment following cancer: The mediating roles of growth, life meaning, and restored just-world beliefs. Journal of Consulting and Clinica Psychology, 76(5), 863-875. https://doi.org/10.1037/a0013348

Popa, R. (2015). Theoretical perspectives upon the return to work of cancer patients: The difficult path of integration in the organization. Social Change Review, 13(2) 113-135. https://doi.org/10.1515/scr-2015-0012

Pullen, L.C. (2013). Hot flashes can affect work and health. Medscape Medical News. Retrieved May 20, 2014, from http://www.webmd.com/menopause/news/ 20130228/hot-flashes-affect-work-health

Renfro-Michel, E.L., Burlew, L.D., \& Robert, T. (2009). The interaction of work adjustment and attachment theory: Employment counselling implications. Journal of Employment Counseling, 46(1), 18-26. https://doi.org/10.1002/j.21611920.2009.tb00062.x

Ross, J. (2007). Occupational therapy and vocational rehabilitation. West Sussex, England: John Willey \& Sons.

Rothmann, S., Jorgensen, L.I., \& Hill, C. (2011). Coping and work engagement in selected South African organisations. SA Journal of Industrial Psychology, 37(1) 1-11. https://doi.org/10.4102/sajip.v37i1.962

Sarkar, S., Sautier, L., Schilling, G., Bokemeyer, K., Koch, U., \& Mehnert, A. (2015) Anxiety and fear of cancer recurrence and its association with supportive care needs and health-care service utilization in cancer patients. Journal of Cancer Survivorship, 9(4), 567-575. https://doi.org/10.1007/s11764-015-0434-2

Stanton, A.L., Rowland, J.H., \& Ganz, P.A. (2015). Life after diagnosis and treatment of cancer in adulthood: Contributions from psychosocial oncology research. American Psychologist, 70(2), 159-174. https://doi.org/10.1037/a0037875

Steiner, J.F., Cavender, T.A., Main, D.S., \& Bradley, C.J. (2004). Assessing the impact of cancer on work outcomes: What are the research needs? Cancer, 101(8), 17031711. https://doi.org/10.1002/cncr.20564

Stergiou-Kita, M., Pritlove, C., Holness, D.L., Kirsh, B., Van Eerd, D., Duncan, A., et al. (2016). Am I ready to return to work? Assisting cancer survivors to determine work readiness. Journal of Cancer Survivorship, 10(4), 699-710. https://doi. org/10.1007/s11764-016-0516-9

Svenningsen, H., Egerod, I., \& Dreyer, P. (2016). Strange and scary memories of the intensive care unit: A qualitative, longitudinal study inspired by Ricoeur's
interpretation theory. Journal of Clinical Nursing, 25(19-20), 2807-2815. https:// interpretation theory. Journal
doi.org/10.1111/jocn.13318

Tamminga, S.J., De Boer, A.G.E.M., Verbeek, J.H.A.M., \& Frings-Dresen, M.H.W. (2012). Breast cancer survivors' views of factors that influence the return-to-work process - A qualitative study. Scandinavian Journal of Work and Environmental Health, - A qualitative study. Scandinavian Journal of Work

Tan, H., Wilson, A., \& Olver, I. (2009). Ricoeur's theory of interpretation: An instrument for data interpretation in hermeneutic phenomenology. International Journal of Qualitative Methods, 8(4), 1-15. https://doi.org/10.1177/160940690900800401

UNISA. (2013). Policy on research ethics. Retrieved February 1, 2017, from http:// www.unisa.ac.za/research/news/wp-content/uploads/2014/06/Policy-onResearch-Ethics-rev-appr-Council-20.09.2013.pdf

Van Muijen, P., Weevers, N.L.E.C., Snels, I.A.K., Duijts, S.F.A., Bruinvels, D.J., Schellart, A.J.M., et al. (2013). Predictors of return to work and employment in cancer survivors: A systematic review. European Journal of Cancer Care, 22(2), 144-160. https://doi.org/10.1111/ecc.12033

Varekamp, I., Heutink, A., Landman, S., Koning, C.E.M., De Vries, G., \& Van Dijk, J.H (2009). Facilitating empowerment in employees with chronic disease: Qualitative analysis of the process of change. Journal of Occupational Rehabilitation, 19, 398-408. https://doi.org/10.1007/s10926-009-9188-x

Wang, M., \& Wanberg, C.R. (2017). 100 years of applied psychology research on individual careers: From career management to retirement. Journal of Applied Psychology, 102(3), 546-653. https://doi.org/10.1037/apl0000143

Wilson-Smith, K., \& Bates, E.A. (2014). Military reserve service and post-tour work adjustment: Exploring lived experiences to inform applied practice. Forensic Update, 115, 28-33.

Yarker, J., Munir, F., Bains, M., Kalawsky, K., \& Haslam, C. (2010). The role of communication and support in return to work following cancer-related absence. Psycho-Oncology, 19(10), 1078-1085. https://doi.org/10.1002/pon.1662 